\title{
BMJ Open Barriers to cervical cancer screening and acceptability of HPV self-testing: a cross-sectional comparison between ethnic groups in Southern Thailand
}

\author{
Anna Gottschlich, ${ }^{1}$ Thanatta Nuntadusit, ${ }^{2}$ Katie R Zarins, ${ }^{3}$ Manila Hada, ${ }^{1}$ \\ Nareerat Chooson, ${ }^{2}$ Surichai Bilheem, ${ }^{2}$ Raphatphorn Navakanitworakul, ${ }^{4}$ \\ Kesara Nittayaboon, ${ }^{4}$ Shama Virani, ${ }^{2}$ Laura Rozek, ${ }^{3}$ Hutcha Sriplung, ${ }^{2}$ Rafael Meza ${ }^{1}$
}

To cite: Gottschlich $A$, Nuntadusit T, Zarins KR, et al. Barriers to cervical cancer screening and acceptability of HPV self-testing: a cross-sectional comparison between ethnic groups in Southern Thailand. BMJ Open 2019;9:e031957. doi:10.1136/ bmjopen-2019-031957

- Prepublication history for this paper is available online. To view these files please visit the journal online (http://dx.doi org/10.1136/bmjopen-2019031957).

HS and RM contributed equally.

Received 28 May 2019

Revised 01 0ctober 2019

Accepted 07 0ctober 2019

Check for updates

(C) Author(s) (or their employer(s)) 2019. Re-use permitted under CC BY-NC. No commercial re-use. See rights and permissions. Published by BMJ.

For numbered affiliations see end of article.

Correspondence to Dr Rafael Meza; rmeza@umich.edu

Dr Hutcha Sriplung; hutcha.s@gmail.com

\section{ABSTRACT}

Background Cervical cancer rates are higher in lowresourced countries than high, partly due to lower rates of screening. Incidence in Thailand is nearly three times higher than in the USA (16.2 vs 6.5 age-standardised incidence), even with Thailand's universal health coverage, which includes screening, suggesting that alternative methods are needed to reduce the burden. We investigated barriers to screening, as well as acceptability of selfcollection human papillomavirus (HPV) testing as a primary form of cervical cancer screening among Buddhist and Muslim communities in Southern Thailand.

Methods 267 women from the Buddhist district of Ranot and Muslim district of Na Thawi, Songkhla were recruited to complete a survey assessing knowledge and risk factors of HPV and cervical cancer. Participants were offered an HPV self-collection test with a follow-up survey assessing acceptability. Samples were processed at Prince of Songkhla University and results were returned to participants.

Results 267 women participated in the study (132 Buddhist, 135 Muslim), 264 (99\%) self-collecting. 98\% reported comfort and ease, and $70 \%$ preferred it to doctorfacilitated cytology. The main predictor of prior screening was religion (92\% Buddhist vs $73 \%$ Muslim reporting prior Pap). After adjustment with multivariate logistic models, Muslim women had an OR of prior Pap of 0.30 compared with Buddhist (95\% Cl: 0.12 to 0.66$)$.

Conclusions Self-collection HPV testing was highly acceptable across religious groups, suggesting that it could be beneficial for cervical cancer reduction in this region. Focus should be put into educating women from all backgrounds about the importance of screening to further improve screening rates among Thai women.

\section{INTRODUCTION}

Cervical cancer is one of the most common cancers in women in Thailand, ${ }^{1}$ with agestandardised incidence and mortality rates at 16.2 and 9.0 per 100000 women, ${ }^{2}$ approximately three times higher than in the USA (6.5 and 1.9 die per 100,000 , respectively). ${ }^{2}$ This disparity is seen between low/
Strengths and limitations of this study

- The Songkhla region of Thailand has a relatively large number of Muslim people living in the region, making it an ideal location to study the differences between Buddhist and Muslim populations.

- Community health volunteers collected the data in participants' native languages and are familiar with the region and the patients.

- The assay used for human papillomavirus detection (Hybribio real-time PCR) is highly sensitive.

- All data was self-reported, so it is likely that there was some misreporting either due to social desirability or recall bias.

- Women testing in their own homes may have more testing anxiety in the absence of healthcare workers, causing lower acceptability of the test.

middle-income countries (LMICs) and highincome countries (HICs) around the world, and there has yet to be a sufficient intervention to eliminate this inequality. Currently, while cervical cancer is not even in the top 10 most common cancers in HICs, it is the second most common cancer among women in LMICs, where $80 \%$ of cervical cancer deaths occur. ${ }^{3}$

Cervical cancer is primarily caused by the human papillomavirus (HPV), a sexually transmitted infection that in most women clears on its own without the knowledge of the infected women. ${ }^{4}{ }^{5}$ However, in some women, infection persists and eventually may cause cervical cancer to develop. Cervical cancer development takes many years, thus allowing for effective screening, prevention, and treatment if detected early. ${ }^{6}$

Today, cervical cancer is considered a preventable disease, in large part due to the Papanicolaou test. ${ }^{7}$ This type of cytologybased screening has significantly reduced 
rates of cervical cancer in HICs but has not had the same effect in LMICs. ${ }^{89}$ This is likely due to lower accessibility to this type of testing, as well as issues with the actual testing in LMICs. Cytology-based screening requires both infrastructure and personnel to which many LMICs may not have access, as well as potentially multiple visits per patient. ${ }^{9-11}$ In addition, due to the inherent subjectivity of this type of test, particularly when samples are evaluated by technicians rather than by pathologists, there is generally low sensitivity in LMICs, ${ }^{12}$ causing many cases to be missed even if a sample is collected. Thus, many LMICs have moved to visual inspection with acetic acid (VIA) in place of Pap screening. VIA can be performed with minimal infrastructure by a properly trained layperson, and screening and treatment can be done in the same visit. ${ }^{8111314}$ However, visual inspection is also subjective ${ }^{15}$; women still need to attend a clinic to receive this test, and equipment needs to be available to perform the treatment.

HPV testing has been shown to be a valid cervical cancer screening modality, and some countries are now recommending it as a primary form of screening. ${ }^{65}$ In particular, studies have shown that the use of primary HPV testing, as compared with cytology alone, significantly lowers the likelihood of the development of precancerous lesions among women undergoing cervical cancer screening, due to increased sensitivity and specificity of cytology testing when restricted to only those women who test positive for HPV. ${ }^{16}$ In addition, some countries are beginning to implement self-collection HPV testing to increase accessibility to screening. ${ }^{17}$ Women can test themselves, in their own home, by collecting a cervical sample using a provided swab. ${ }^{18}$ If a woman tests positive for high-risk HPV, then she will need to access follow-up care at a clinic; however, if the woman tests negative, she simply needs to be tested periodically (usually in 5-year increments). This can reduce the number of times that women need to travel to clinics for screening or follow-up care, which could eventually also reduce the burden on the healthcare system.

The rates of cervical cancer in Thailand have been declining since 2002, ${ }^{19-21}$ when a national cervical cancer screening programme was implemented, aiming to screen all women between the ages of 35 and 60 at 5 -year intervals. In 2004, the programme added VIA to the already existing Pap smear programme. The three public health insurance programmes in Thailand cover the costs of cervical cancer screening in their benefits packages. ${ }^{1}$ However, the decline in cervical cancer has been slower than expected (cervical cancer is still the second most common cancer among women in Thailand, causing over $10 \%$ of new female cases in $2018^{22}$ ), thus calling for improvements in the current screening programme. ${ }^{19}$ This is largely due to the lower than ideal uptake of cervical cancer screening: a survey conducted in 2009 estimated that only $59.7 \%$ of women in Thailand have ever been screened for cervical cancer. ${ }^{1}$ Uptake is even lower among the minority Muslim population (making up only $5 \%$ of the country) as compared with the majority Buddhist population (94\% of the population) ${ }^{23}$ in Thailand (eg, $46.7 \%$ vs $60.4 \%$ reporting ever having cervical cancer screening in the 2009 Health and Welfare Survey, ${ }^{1}$ respectively), perhaps due to reports of embarrassment and wanting to avoid uncovering parts of their bodies during exams, due to the high value that the Muslim religion places on modesty. ${ }^{1}$ One previous study investigated the acceptability of self-collection HPV testing in women in Thailand. Acceptability was found to be quite high, but participants were worried about both the cost and the reliability of the results from this type of testing. ${ }^{24}{ }^{25}$ However, no previous studies have specifically looked at women from diverse ethnic groups in Thailand to determine whether HPV self-collection testing is more useful in certain populations than others.

In this study we investigated the differences in access and barriers to cervical cancer screening between Buddhist and Muslim women in Southern Thailand and examined potential screening predictors. We also assess willingness to use and acceptability of self-collection HPV testing methods in these communities.

\section{MATERIAL AND METHODS \\ Study design and sampling}

The study was designed as a cross-sectional survey, with a maximum of one interaction per participant. Data collection took place in two districts within the Songkhla Province of Southern Thailand: Na Thawi, in the southern part of Songkhla Province, and Ranot, in the northernmost region. Each of these districts is fairly religiously homogenous, with Na Thawi and Ranot being predominantly Muslim and Buddhist, respectively. Women were recruited from lists of the target population for screening provided by reproductive health clinics in these districts, half located in Na Thawi and half in Ranot. The primary care centres made this list by randomly selecting from the entire female population in the province's health office database and then distributed 12-15 names to each healthcare volunteer, irrespective of the volunteer's religion. The volunteers then visited their assigned households and set up appointments with eligible women for screening at public primary care clinics. When women came into the clinics, they were asked by a community health worker whether they would like to participate in the study. If they said yes, they were consented and then enrolled, after which a survey was administered, and selfcollection HPV testing was offered.

Recruitment took place from July to December in 2017. We aimed to recruit 130 women from each region, according to power calculations. Women had to be over the age of 18 to participate, and between the ages of 25 and 60 to participate in the self-collection sampling portion of the study. For the self-collection sampling, women were ineligible to participate if they were pregnant or menstruating, had a previous history of cervical cancer or had previously had a hysterectomy. 


\section{Data collection tools}

Data was collected using a 150-question survey that assessed sexual behaviour and practices, known risk factors associated with HPV, and knowledge of HPV infection and its association with cervical cancer. The survey was developed using similar questions to prior studies of health risk factors, ${ }^{26} 27$ and was originally written in English and then translated into Thai by native Thai investigators from Prince of Songkhla University (PSU). This survey has also been translated into other languages for similar studies occurring in other countries. ${ }^{18}$ Prior to data collection, the survey was piloted on 10 women, both Buddhist and Muslim, sampled randomly in the Singha Nakhon district. Data were collected using the Qualtrics survey application. ${ }^{28}$ Study research assistants read the survey aloud to each participant and recorded her responses on a tablet. At the end of each day, survey responses were uploaded to a secure server.

In addition, on completion of the survey, eligible women were offered a self-collection cervical sample kit to be tested for HPV. The kit (HerSwab) ${ }^{29}$ was manufactured by Eve Medical and has previously been shown to be acceptable among other populations. ${ }^{18}$ If a woman chose to self-collect, the community health volunteer gave her the kit and an illustrated 'Instructions-for-Use' card and explained the sampling procedure. Women then collected a sample in a private room and returned the swab to the community health volunteer. Samples were transported to the Department of Biomedical Sciences at PSU following collection and stored until testing occurred.

\section{Laboratory analysis}

Samples were analysed at the Department of Biomedical Sciences at PSU using a 13 high-risk HPV (hrHPV) real-time PCR kit (Hybribio Limited), which detects HPV types $16,18,31,33,35,39,45,51,52,56,58,59,68 .{ }^{30}$ Positive and negative controls were included on each plate, and internal controls were evaluated for each sample. Results were provided to the community health centres in $\mathrm{Na}$ Thawi and Ranot, where the community health volunteers were able to coordinate follow-up care for participants. If the HPV results were positive, it was suggested that they receive follow-up care (in the form of a Pap test) from their local health centre, and if negative were told to repeat testing in 3 years.

\section{Statistical analysis}

As this is mainly a descriptive study to identify any differences in screening practices between two ethnic groups, all survey questions were examined. Variables were grouped into four areas: demographics, sexual and general health, cervical cancer and HPV, and healthcare access. In addition, we compared women who reported having prior cervical cancer screening to women who reported no prior screening, using the variables mentioned above, with both univariate analyses and multivariate logistic models, adjusted for literacy, age and number of children as a proxy for previous encounters with health care services. Finally, we investigated the acceptability of the self-collection test among women who were willing to use it by asking four questions after collection: 'How comfortable was the test?', 'How easy was the test?', 'Are you willing to continue to take this test periodically in the future?' and 'Do you prefer self-collection or Pap testing?'.

We compared responses between Buddhist and Muslim women using two-sided t-tests and $\chi^{2}$ tests for continuous and categorical variables, respectively. A similar procedure was used to compare women who had previously been screened for cervical cancer with those who had not. Multivariate logistic models were then run to examine potential predictors for prior screening, after adjusting for confounders. Finally, a descriptive analysis was conducted to assess acceptability of the self-swab test, where an $\alpha<0.05$ was considered significant. All analyses were conducted using R V.3.4.4.

\section{Patient and public involvement}

Participants and the public were first involved at the design and piloting stages of the study. Research questions and outcome measures were developed using prior surveys assessing use of healthcare in other low/middleincome settings ${ }^{18}$ and direct feedback was received from clinic staff. During piloting, feedback was also received from participants and clinic workers. Patients at local health clinics were directly approached by study personnel inviting them to participate in the study and discussing with them the format and purpose of the study. While participants were not asked about the time required to participate in the research, the post-sampling survey explicitly asked participants about the acceptability and perceptions of self-sampling to assess the burden of the intervention being investigated. To disseminate study results to participants and the community, we plan to conduct educational and study dissemination sessions. These will be planned directly in collaboration with community-based clinic personnel and other representatives from the community.

\section{Ethical approval}

All participants were given oral and printed informed consent before participation. This consent was documented by signature from the participant on the consent form and all consent forms are filed in a locked cabinet at PSU.

\section{RESULTS}

\section{Demographics}

267 women were recruited from the community health centres in the Ranot $(n=132)$ and $\mathrm{Na}$ Thawi $(n=135)$ districts of Songkla Province in Southern Thailand. All 132 women from Ranot identified as Buddhist and all 135 from Na Thawi identified as Muslim. The average age of the Buddhist population was 51.3 years, while in the 
Table 1 Demographics

\begin{tabular}{|c|c|c|c|c|}
\hline Variable & $\begin{array}{l}\text { Total } \\
\mathrm{n}=267 \\
\text { Prop (N) } \\
\text { Mean (SD) }\end{array}$ & $\begin{array}{l}\text { Buddhist } \\
\mathrm{n}=132 \\
\text { Prop (N) } \\
\text { Mean (SD) }\end{array}$ & $\begin{array}{l}\text { Muslim } \\
\mathrm{n}=135 \\
\text { Prop (N) } \\
\text { Mean (SD) }\end{array}$ & $P$ value \\
\hline Age & $50.44(5.83)$ & $51.27(6.08)$ & $49.63(5.48)$ & $0.02^{*}$ \\
\hline Literate & $0.88(236)$ & $0.96(127)$ & $0.81(109)$ & $<0.001^{*}$ \\
\hline Education & & & & $0.003^{*}$ \\
\hline None & $0.06(15)$ & $0.00(0)$ & $0.11(15)$ & \\
\hline Primary & $0.67(179)$ & $0.71(94)$ & $0.63(85)$ & \\
\hline Secondary & $0.18(49)$ & $0.18(24)$ & $0.19(25)$ & \\
\hline Vocational & $0.05(13)$ & $0.06(8)$ & $0.04(5)$ & \\
\hline Academic college & $0.04(11)$ & $0.05(6)$ & $0.04(5)$ & \\
\hline Postgraduate & $0.00(0)$ & $0.00(0)$ & $0.00(0)$ & \\
\hline \multicolumn{5}{|l|}{ Civil status } \\
\hline Single & $0.00(0)$ & $0.00(0)$ & $0.00(0)$ & $<0.001^{*}$ \\
\hline Married & $0.69(184)$ & $0.80(106)$ & $0.58(78)$ & \\
\hline Common law & $0.21(55)$ & $0.09(12)$ & $0.32(43)$ & \\
\hline Separated & $0.01(2)$ & $0.02(2)$ & $0.00(0)$ & \\
\hline Divorced & $0.04(11)$ & $0.04(5)$ & $0.04(6)$ & \\
\hline Widowed & $0.04(10)$ & $0.02(3)$ & $0.05(7)$ & \\
\hline Marriage age & $21.26(5.35)$ & $22.85(5.98)$ & $19.72(4.15)$ & $<0.001^{*}$ \\
\hline Past year income $\left(\mathrm{THB}^{\star \star}\right)$ & & & & 0.27 \\
\hline 0-79999 & $0.33(78)$ & $0.34(39)$ & $0.31(39)$ & \\
\hline 80000-119999 & $0.28(67)$ & $0.31(35)$ & $0.25(32)$ & \\
\hline $120000-179999$ & $0.18(44)$ & $0.19(22)$ & $0.17(22)$ & \\
\hline 180000 or more & $0.21(51)$ & $0.16(18)$ & $0.26(33)$ & \\
\hline
\end{tabular}

${ }^{*} \mathrm{p}<0.05$

${ }^{* \star}$ Thai Baht (Thailand currency)

Muslim population it was 49.6 years. There were several statistically significant demographic differences between the Buddhist and Muslim women in the sampled population (table 1). Buddhist women on average reported higher literacy (96\% vs $81 \%, \mathrm{p}<0.001)$ and education levels $(p=0.003)$. In addition, Muslim women were more likely than Buddhist women to be in a common law relationship instead of marriage $(p<0.001)$. However, there were no statistically significant differences in income between the two populations.

\section{Prior access to healthcare and barriers to screening}

Buddhist and Muslim women appeared to access healthcare differently in these communities (table 2). Buddhist women reported accessing more medical services and using health services more frequently than Muslim women. Notably, a higher percentage of Buddhist women reported prior Pap screening (92\% vs 73\%, respectively, $\mathrm{p}<0.001$ ), as well as more recent screening, than Muslim women. Among women who have not been screened for cervical cancer, the most common reported reason for not screening among Buddhist women was no perceived health issues, and thus no reason to seek medical attention (40\%), while for Muslim it was either a lack of knowledge that they should be screened or feelings of fear and embarrassment about screening $(35 \%$ and $41 \%$, respectively). In addition, Buddhist and Muslim women both reported that a doctor telling them they would need the test, and reduced cost of the test would be motivators to getting tested. Finally, Muslim women were less likely than Buddhist women to use oral contraceptives $(41 \%$ vs $67 \%$, respectively, $\mathrm{p}<0.001$ ).

\section{Acceptability of self-collection}

There was an almost universal acceptance of self-collection among this population (table 3). Ninety-eight percent of women found the test both comfortable and easy, and $100 \%$ said they would be willing to continue to use this test as a preliminary form of cervical cancer screening. Among women who reported prior Pap testing, both communities preferred self-swab to Pap testing. However, more Buddhist women preferred Pap and self-collection co-testing than Muslim women $(33 \%$ vs $19 \%$, respectively, $\mathrm{p}=0.05$ ), while more Muslim women than Buddhist 
Table 2 Sexual and health history

\begin{tabular}{|c|c|c|c|c|}
\hline Variable & $\begin{array}{l}\text { Total } \\
\mathrm{n}=267 \\
\text { Prop (N) } \\
\text { Mean (SD) }\end{array}$ & $\begin{array}{l}\text { Buddhist } \\
\mathrm{n}=132 \\
\text { Prop (N) } \\
\text { Mean (SD) }\end{array}$ & $\begin{array}{l}\text { Muslim } \\
\mathrm{n}=135 \\
\text { Prop (N) } \\
\text { Mean (SD) }\end{array}$ & $P$ value \\
\hline University hospital & $0.27(73)$ & $0.34(45)$ & $0.21(28)$ & $0.047^{\star}$ \\
\hline Primary care facility & $0.99(264)$ & $1.00(132)$ & $0.98(132)$ & 1 \\
\hline $\begin{array}{l}\text { Other } \\
\text { (private hospital, } n=2 \text {; } \\
\text { clinic, } n=83 \text { ) }\end{array}$ & $0.32(85)$ & $0.16(21)$ & $0.47(64)$ & $<0.001^{*}$ \\
\hline Last health visit & & & & $<0.001^{*}$ \\
\hline Less than a month & $0.22(59)$ & $0.30(40)$ & $0.14(19)$ & \\
\hline six months-1 year & $0.18(48)$ & $0.15(20)$ & $0.21(28)$ & \\
\hline $1-5$ years & $0.14(37)$ & $0.09(12)$ & $0.19(25)$ & \\
\hline More than 5 years & $0.05(14)$ & $0.01(1)$ & $0.10(13)$ & \\
\hline Never & $0.03(7)$ & $0.03(4)$ & $0.02(3)$ & \\
\hline Use healer & $0.18(49)$ & $0.11(14)$ & $0.26(35)$ & $0.002^{*}$ \\
\hline Had Pap & $0.82(219)$ & $0.92(121)$ & $0.73(98)$ & $<0.001^{*}$ \\
\hline Last Pap & & & & $0.007^{*}$ \\
\hline Less than 6 months & $0.07(16)$ & $0.08(10)$ & $0.06(6)$ & \\
\hline Less than 1 year & $0.30(66)$ & $0.37(45)$ & $0.21(21)$ & \\
\hline $3-4$ & $0.39(86)$ & $0.45(55)$ & $0.32(31)$ & \\
\hline Five or more & $0.18(39)$ & $0.21(26)$ & $0.13(13)$ & \\
\hline Don't know & $0.01(2)$ & $0.02(2)$ & $0.00(0)$ & \\
\hline Main reason no Pap & & & & $0.08^{*}$ \\
\hline None/never thought of it & $0.13(6)$ & $0.10(1)$ & $0.14(5)$ & \\
\hline Didn't know needed it & $0.32(15)$ & $0.20(2)$ & $0.35(13)$ & \\
\hline Haven't had any problems & $0.15(7)$ & $0.40(4)$ & $0.08(3)$ & \\
\hline Too expensive & $0.00(0)$ & $0.00(0)$ & $0.00(0)$ & \\
\hline Too painful/embarrassing & $0.36(17)$ & $0.20(2)$ & $0.41(15)$ & \\
\hline Other & $0.04(2)$ & $0.10(1)$ & $0.03(1)$ & \\
\hline Doctor motivation & & & & $<0.001^{\star}$ \\
\hline Extremely likely & $0.60(161)$ & $0.73(96)$ & $0.48(65)$ & \\
\hline Very likely & $0.15(40)$ & $0.11(14)$ & $0.19(26)$ & \\
\hline Somewhat likely & $0.12(32)$ & $0.09(12)$ & $0.15(20)$ & \\
\hline Not very likely & $0.11(30)$ & $0.08(10)$ & $0.15(20)$ & \\
\hline Don't know & $0.01(4)$ & $0.00(0)$ & $0.03(4)$ & \\
\hline \multicolumn{5}{|l|}{ Payment motivation } \\
\hline Extremely likely & $0.51(137)$ & $0.64(85)$ & $0.39(52)$ & $<0.001^{\star}$ \\
\hline
\end{tabular}


Table 2 Continued

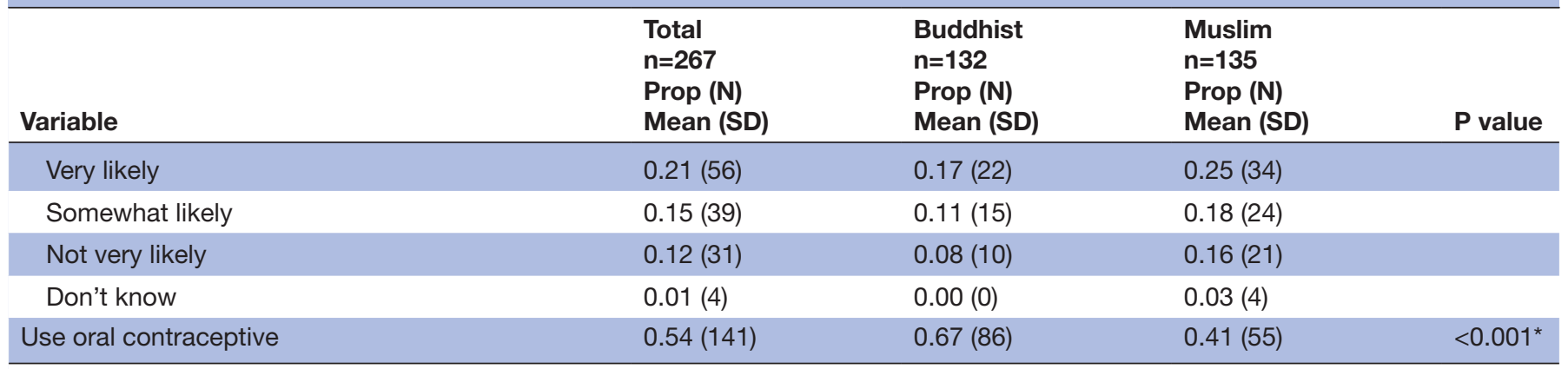

${ }^{*} p<0.05$

women preferred self-swab alone ( $77 \%$ vs $64 \%, \mathrm{p}=0.05)$. Both Muslim and Buddhist women prefer testing to be done in a medical setting, but Muslim women are more likely to prefer self-collection to doctor-collection $(94 \%$ reporting preference for self-collection vs $77 \%$ ) than Buddhist women.

\section{High-risk HPV (hrHPV) positivity}

Nearly all of the participants chose to self-collect a sample to be tested for HPV (98\% and 99\% of Buddhist and
Muslim women, respectively). The three women who did not self-collect had a sample collected by a physician, and thus we have HPV results for all 267 participants. Of these women, only $5 \%$ overall $(n=13)-7 \%$ of all conclusive tests - tested positive for hrHPV: 5 Buddhist and 8 Muslim (no statistically significant differences between the two religious groups, shown in table 4 ).

\begin{tabular}{|c|c|c|c|c|}
\hline Variable & $\begin{array}{l}\text { Total } \\
\mathrm{n}=267 \\
\text { Prop (N) } \\
\text { Mean (SD) }\end{array}$ & $\begin{array}{l}\text { Buddhist } \\
n=132 \\
\text { Prop (N) } \\
\text { Mean (SD) }\end{array}$ & $\begin{array}{l}\text { Muslim } \\
n=135 \\
\text { Prop (N) } \\
\text { Mean (SD) }\end{array}$ & $P$ value \\
\hline Self-collected sample & $0.99(264)$ & $0.98(130)$ & $0.99(134)$ & 0.62 \\
\hline Comfort & & & & 1.00 \\
\hline Comfortable & $0.98(259)$ & $0.98(128)$ & $0.97(131)$ & \\
\hline Neutral & $0.02(5)$ & $0.02(2)$ & $0.02(3)$ & \\
\hline Uncomfortable & $0.00(0)$ & $0.00(0)$ & $0.00(0)$ & \\
\hline Ease & & & & 1.00 \\
\hline Easy & $0.98(258)$ & $0.98(127)$ & $0.97(131)$ & \\
\hline Neutral & $0.02(6)$ & $0.02(3)$ & $0.02(3)$ & \\
\hline Difficult & $0.00(0)$ & $0.00(0)$ & $0.00(0)$ & \\
\hline Willing to retake & $1.00(264)$ & $1.00(130)$ & $1.00(134)$ & 1.00 \\
\hline Preference $^{* *}$ & & & & $0.05^{*}$ \\
\hline Self-swab kit & $0.70(153)$ & $0.64(78)$ & $0.77(75)$ & \\
\hline Pap smear & $0.03(6)$ & $0.02(2)$ & $0.04(4)$ & \\
\hline Both & $0.27(59)$ & $0.33(40)$ & $0.19(19)$ & \\
\hline Neither & $0.00(1)$ & $0.01(1)$ & $0.00(0)$ & \\
\hline Test pref location & & & & $<0.001^{*}$ \\
\hline At home & $0.18(49)$ & $0.04(10)$ & $0.15(39)$ & \\
\hline At healthcare centre & $0.82(218)$ & $0.96(122)$ & $0.85(96)$ & \\
\hline Test pref collector & & & & $<0.001^{*}$ \\
\hline My health personnel & $0.14(38)$ & $0.23(30)$ & $0.06(8)$ & \\
\hline Myself & $0.86(225)$ & $0.77(100)$ & $0.94(125)$ & \\
\hline
\end{tabular}

${ }^{*} p<0.05$

${ }^{\star} \star A$ Among women who reported ever receiving a Pap test. 


\begin{tabular}{|c|c|c|c|c|}
\hline Variable & $\begin{array}{l}\text { Total } \\
\mathrm{n}=264 \\
\text { Prop (N) } \\
\text { Mean (SD) }\end{array}$ & $\begin{array}{l}\text { Buddhist } \\
n=132 \\
\text { Prop (N) } \\
\text { Mean (SD) }\end{array}$ & $\begin{array}{l}\text { Muslim } \\
n=135 \\
\text { Prop (N) } \\
\text { Mean (SD) }\end{array}$ & $P$ value \\
\hline hrHPV status & & & & 0.71 \\
\hline Positive & $0.049(13)$ & $0.039(5)$ & $0.059(8)$ & \\
\hline Negative & 0.697 (184) & $0.713(92)$ & 0.681 (92) & \\
\hline Inconclusive & $0.254(67)$ & $0.248(32)$ & 0.259 (35) & \\
\hline
\end{tabular}

hrHPV, high-risk human papillomavirus.

\section{Predictors of prior screening}

Women who report ever being screened were more likely to be Buddhist than Muslim ( $55 \%$ vs $45 \%$, p<0.001), were on average of a higher education $(\mathrm{p}=0.03)$ and literacy level $(91 \%$ vs $74 \%, \mathrm{p}=0.001)$, had a later sexual debut (21.44 years vs 19.02 years, $\mathrm{p}<0.001$ ), married at an older age (21.74 years vs 19.02 years, $\mathrm{p}<0.001)$, had higher utilisation of healthcare and contraception and had fewer pregnancies and children than those who report never being screened (table 5). In addition, those who reported ever screening had higher rates of knowledge of HPV than those who reported never screening $(47 \%$ vs $30 \%$, $\mathrm{p}=0.04)$. There was no difference in age for those who report ever versus never screened, which is interesting, as generally older women (who have had more time to access screening) tend to be more likely to have ever screened than younger women.

Ethnicity appears to be the main effect for likelihood to have previously accessed cervical cancer screening (shown in table 6), with Muslim women being significantly less likely to have had prior screening ( $\mathrm{OR}=0.22$, $95 \% \mathrm{CI}=0.10,0.45)$. Variables such as literacy levels, age and number of children (as a proxy for prior experiences with healthcare services) could confound this relationship; however, multivariate logistic models showed that even after adjusting for relevant covariates, the association remained significant $(\mathrm{OR}=0.30,95 \% \mathrm{CI}=0.12,0.66)$.

\section{DISCUSSION}

Our study found hrHPV prevalence of $5 \%$, which is significantly lower than rates of hrHPV seen in many other settings, but similar to studies that have been conducted in Thailand. ${ }^{31}$

In addition, the findings from this study suggest significant differences in demographics, sexual and health history, and knowledge of HPV and cervical cancer between Buddhist and Muslim women in Songkhla, Thailand. The results of this study demonstrate the high potential and acceptability of self-collection HPV testing as a primary form of cervical cancer screening in these communities. Our results also suggest that, currently, some subpopulations in Thailand may have a more difficult time accessing health care than others, despite the availability of high-quality, universal healthcare. The Muslim women who participated in our study had lower levels of literacy and education than their Buddhist counterparts, both of which are documented barriers to healthcare accessibility. ${ }^{1}{ }^{32}$ Furthermore, Buddhist women utilised health care services and contraceptives more frequently and had higher rates of prior cervical cancer screening than Muslim women. This is likely because Muslim women report lower rates of knowledge of cervical cancer and higher rates of fear and embarrassment resulting from cervical cancer screening. This is consistent with research that has shown that cultural differences, including language differences, lead to lower rates of access to healthcare among religious minorities in Thailand. ${ }^{33-37}$ However, our study shows that selfscreening is acceptable, and even preferred, in women from both religious groups to other modalities. While the majority of women still reported a preference for testing in a healthcare setting as opposed to in the home, they also preferred self-testing over doctor-testing. This highlights that it is important to assess not only the acceptability of self-sampling but also the preferred settings for different social groups. Self-collection HPV sampling could thus help mitigate the barriers to cervical cancer screening that Muslim women in Thailand encounter: it is private and can be done by a woman in her own home, thus reducing the embarrassment and fear associated with receiving a Pap at a doctor's office.

This study has many strengths that have allowed us to thoroughly investigate accessibility and acceptability of cervical cancer screening via HPV testing across different ethnic groups in Southern Thailand. The Songkhla region of Thailand is an ideal location to study the differences between Buddhist and Muslim populations, as there is a relatively large number of Muslim people living in this region. In addition, the data were collected by community health volunteers who are familiar with the population, often know the patients personally and interact with them on a regular basis and speak the language fluently. We were also able to collect the data using the Qualtrics app on tablets, thus reducing the chance of data entry errors when moving from paper to computer databases. The self-collection swabs that we chose came with an 'Instructions-for-Use' card that was translated into the participants' native language and there was always a research assistant available to answer questions and explain directions during collection, allowing for a better understanding of the collection method. Finally, the assay used for HPV detection (Hybribio RT-PCR) is highly sensitive. However, there are also limitations to this study. All data were self-reported, and since there were questions that were sensitive in nature, it is likely that there was some misreporting either due to social desirability or recall bias. Women may have over-reported prior screening if they believed that was the 'correct' behaviour or they simply may not remember accurately when or if they had received this test. Number of sexual partners may be misreported for similar reasons. In addition, since 
Table 5 Predictors of prior screening

\begin{tabular}{|c|c|c|c|}
\hline Variable & $\begin{array}{l}\text { Prior screen } \\
\mathrm{n}=219 \\
\text { Prop (N) } \\
\text { Mean (SD) }\end{array}$ & $\begin{array}{l}\text { No screen } \\
n=47 \\
\text { Prop (N) } \\
\text { Mean (SD) }\end{array}$ & $P$ value \\
\hline Age & $50.51(5.84)$ & $50.04(5.90)$ & 0.62 \\
\hline Ethnicity & & & $<0.001^{*}$ \\
\hline Buddhist & 0.55 (121) & $0.21(10)$ & \\
\hline Muslim & $0.45(98)$ & $0.79(37)$ & \\
\hline Education & & & $0.03^{*}$ \\
\hline None & $0.05(10)$ & $0.11(5)$ & \\
\hline Primary & $0.64(141)$ & $0.79(37)$ & \\
\hline Secondary & $0.20(44)$ & $0.11(5)$ & \\
\hline Vocational & $0.06(13)$ & $0.00(0)$ & \\
\hline Academic college & $0.05(11)$ & $0.00(0)$ & \\
\hline Postgraduate & $0.00(0)$ & $0.00(0)$ & \\
\hline Past year income & & & 0.41 \\
\hline 0-79999 & $0.34(66)$ & $0.29(12)$ & \\
\hline $80000-119999$ & $0.26(52)$ & $0.33(14)$ & \\
\hline $120000-179999$ & $0.17(34)$ & $0.24(10)$ & \\
\hline 180000 or more & $0.23(45)$ & $0.14(6)$ & \\
\hline Lifetime sexual partners & $1.20(0.61)$ & $1.13(0.40)$ & 0.34 \\
\hline Marriage age & $21.74(5.63)$ & $19.02(3.00)$ & $<0.001^{*}$ \\
\hline Literate & $0.91(200)$ & $0.74(35)$ & $0.001^{*}$ \\
\hline Frequency of health visits & & & 0.17 \\
\hline More than $1 /$ week & $0.00(0)$ & $0.00(0)$ & \\
\hline $1 /$ week & $0.00(1)$ & $0.00(0)$ & \\
\hline $1 /$ month & $0.13(8)$ & $0.06(3)$ & \\
\hline Every 3-6 months & $0.46(101)$ & $0.34(16)$ & \\
\hline 1/year & $0.21(47)$ & $0.34(16)$ & \\
\hline Less than $1 /$ year & $0.19(42)$ & $0.26(12)$ & \\
\hline Breast exam & $0.24(53)$ & $0.09(4)$ & $0.02^{*}$ \\
\hline Mammogram & $0.16(9)$ & $1.00(4)$ & $0.001^{*}$ \\
\hline Use Depo-Provera & $0.48(103)$ & $0.40(18)$ & 0.41 \\
\hline Use birth control pill & $0.56(121)$ & $0.42(19)$ & 0.10 \\
\hline Use condom & $0.34(73)$ & $0.11(5)$ & $0.002^{*}$ \\
\hline Number of pregnancies & 3.39 (1.72) & $4.04(2.06)$ & $0.05^{\star}$ \\
\hline Number of children & $2.94(1.38)$ & $3.68(1.72)$ & $0.01^{*}$ \\
\hline Age at first pregnancy & $23.69(5.54)$ & $21.23(3.74)$ & $<0.001^{*}$ \\
\hline Family member with CC & $0.04(8)$ & $0.00(0)$ & 0.13 \\
\hline Age first sex & $21.44(5.29)$ & $19.02(2.72)$ & $<0.001^{*}$ \\
\hline Knowledge of HPV & $0.47(102)$ & $0.30(14)$ & $0.04^{*}$ \\
\hline
\end{tabular}

${ }^{*} p<0.05$

CC, Cervical Cancer; HPV, human papillomavirus.

participation in the study occurred in health centers, we may not have a representative sample of the community if certain groups chose not to come to the clinics, although in general, health care utilisation is high overall in Thailand. ${ }^{38}$ Finally, since women performed the selfswab collection at the clinic, they may have a sense of confidence that there are healthcare workers nearby if anything were to go wrong. Women testing in their own 
Table 6 Muslim ethnicity (vs Buddhist) as a predictor of prior cervical cancer screening

\begin{tabular}{lll}
\hline Model & OR & $\mathbf{9 5 \%} \mathbf{C l}$ \\
\hline Crude & 0.22 & 0.10 to 0.45 \\
Adjusted* $^{*}$ & 0.30 & 0.12 to 0.66
\end{tabular}

*Model adjusted for literacy, age and number of children (as a proxy for previous encounters with healthcare services).

homes may have more testing anxiety in the absence of healthcare workers.

This study provided data showing similar results to other HPV self-collection acceptability studies that have been conducted in Thailand and elsewhere. In our data set, approximately $80 \%$ of women report having ever screened for cervical cancer; a similar percentage was found by Oranratanaphan et al. ${ }^{24}$ In addition, we found high rates of acceptability of this type of test, which has been shown by most self-collection studies in countries around the world, including Thailand. For example, Phoolcharoen et al and Oranratanaphan et al found that over $90 \%$ and over $80 \%$ of the women they asked to selfcollect a cervical sample found the test both easy and comfortable, respectively, ${ }^{24}{ }^{25}$ similar to what was seen in this study. However, here we show that although acceptability is high across religious groups, there may be some subtle differences to consider. In our study, Buddhist women, who report more access to health care and less fear and embarrassment of screening, were more likely to want both self-collection HPV testing as well as healthcare provider-administered cytology-based screenings (also known as co-testing), while Muslim women were much more likely to want only self-screening for HPV, potentially related to differing levels of trust in health care professionals between the groups. These results imply that tailored screening programmes may be ideal for settings where there are distinct and differing barriers to screening in different groups of women, such as programmes providing access to both HPV testing and Pap smears, with the option of self-collection if desired. Providing more accessible forms of screening to women who are not as likely to have access to traditional forms of screening could increase screening uptake, thus reducing the incidence of and mortality due to cervical cancer.

As this study was conducted exclusively in clinics, it still needs to be determined if self-collection HPV testing would perform similarly at the community level. Thus, a natural next step would be to investigate the feasibility of a community-based self-collection HPV testing programme, where women receive swabs and collect samples at homes and then samples are transferred to labs for testing. This type of programme could potentially greatly increase the rates of cervical cancer screening across certain communities.

However, improvement of screening alone will not improve health outcomes if women who receive abnormal results do not have access to follow-up care. Thus, it is vital to study linkage to treatment for those who screen positive, independently of the screening collection method.

\section{CONCLUSIONS}

HPV self-collection appears to be highly acceptable in these communities, with particularly high rates of preferability among Muslim women. Further work should be done to assess the impact and costs of cervical cancer programme including HPV testing and self-collection in Thailand. Due to the simplicity of testing and sensitivity of the assay, HPV self-collection sampling has the potential to improve screening across many different populations, complementing, or even replacing in some settings, current methods for cervical cancer screening.

\section{Author affiliations}

${ }^{1}$ Department of Epidemiology, School of Public Health, University of Michigan, Ann Arbor, Michigan, USA

${ }^{2}$ Epidemiology Unit, Faculty of Medicine, Prince of Songkla University, Hat Yai, Thailand

${ }^{3}$ Department of Environmental Health Sciences, School of Public Health, University of Michigan, Ann Arbor, United States

${ }^{4}$ Department of Biomedical Sciences, Faculty of Medicine, Prince of Songkla University, Hat Yai, Thailand

Contributors AG: survey design, analysis design and execution, drafted the manuscript; TN, NC and SB: data collection, survey design, manuscript review and approval; KRZ: study design, data collection, surveyor training, manuscript review and approval; $\mathrm{MH}$ and SV: study design, questionnaire design and implementation, manuscript review and approval; RN and KN: laboratory analysis, study design, manuscript review and approval; LR: study design, questionnaire design and implementation, analysis design, manuscript drafting and approval; HS: study design and supervision, questionnaire design and implementation, analysis design, stakeholder engagement, manuscript drafting and approval; RM: study design and supervision, questionnaire design, analysis design, manuscript drafting and approval, obtained funding for the study

Funding We acknowledge funding from the University of Michigan School of Public Health (U-M SPH), the U-M SPH Office of Global Public Health, the U-M Center for South East Asian Studies, the U-M Global Cancer Initiative and the Fogarty International Center (04R25TW009345). Research reported in this publication was also supported by the National Cancer Institute of Health under Award Number P30CA046592. The content is solely the responsibility of the authors and does not necessarily represent the official views of the National Institutes of Health.

Competing interests None declared.

Patient consent for publication Not required.

Ethics approval Ethical approval was granted by both the University of Michigan (HUM00114785) and the PSU Research Ethics Committee (REC 59-235-18-1).

Provenance and peer review Not commissioned; externally peer reviewed.

Data availability statement Data are available upon reasonable request.

Open access This is an open access article distributed in accordance with the Creative Commons Attribution Non Commercial (CC BY-NC 4.0) license, which permits others to distribute, remix, adapt, build upon this work non-commercially, and license their derivative works on different terms, provided the original work is properly cited, appropriate credit is given, any changes made indicated, and the use is non-commercial. See: http://creativecommons.org/licenses/by-nc/4.0/.

\section{REFERENCES}

1 Mukem S, Meng Q, Sriplung $\mathrm{H}$, et al. Low coverage and disparities of breast and cervical cancer screening in Thai women: analysis of national representative household surveys. Asian Pacific Journal of Cancer Prevention 2016;16:8541-51. 
2 International agency for research on cancer. Global cancer Observatory.

3 Griffiths M. Screening for cervical cancer in developing countries. World Heal Organ 2002;984.

4 Walboomers JMM, Jacobs MV, Manos MM, et al. Human papillomavirus is a necessary cause of invasive cervical cancer worldwide. J Pathol 1999;189:12-19.

5 Luciani S, Cabanes A, Prieto-Lara E, et al. Cervical and female breast cancers in the Americas: current situation and opportunities for action. Bull World Health Organ 2013;91:640-9.

6 Vesco K, Whitlock E, Eder M, et al. Screening for Cervical Cancer: A Systematic Evidence Review for the U.S. Preventive Services Task Force [Internet]. AHRQ Publ 2011:11-5156.

7 Fields MM. New cervical cancer screening guidelines: was the annual Pap too much of a good thing? J Adv Pract Oncol 2013;4:59-64.

8 Sahasrabuddhe VV, Parham GP, Mwanahamuntu MH, et al. Cervical cancer prevention in low- and middle-income countries: feasible, affordable, essential. Cancer Prev Res 2012;5:11-17.

9 Sankaranarayanan R, Budukh AM, Rajkumar R. Effective screening programmes for cervical cancer in low- and middle-income developing countries. Bull World Health Organ 2001;79:954-62.

10 Boggan JC, Walmer DK, Henderson G, et al. Vaginal selfsampling for human papillomavirus infection as a primary cervical cancer screening tool in a Haitian population. Sex Transm Dis 2015;42:655-9.

11 Ditzian LR, David-West G, Maza M, et al. Cervical cancer screening in low- and middle-income countries. Mt Sinai J Med 2011;78:319-26.

12 Barut MU, Kale A, Kuyumcuoğlu U, et al. Analysis of sensitivity, specificity, and positive and negative predictive values of smear and colposcopy in diagnosis of premalignant and malignant cervical lesions. Med Sci Monit 2015;21:3860-7.

13 Nahar K, Nessa A, Shamim S, et al. Role of via in cervical cancer screening in low-resource countries. Mymensingh Med J 2011;20.

14 African Population and Health Research Center, International Agency for Research on Cancer WHO. Prevention of cervical cancer through screening using visual inspection with acetic acid (via) and treatment with cryotherapy. A demonstration project in six African countries: Malawi, Madagascar, Nigeria, Uganda, the United Republic of Tanzania, and Za. Int Agency Res Cancer 2012;33.

15 Moses E, Pedersen HN, Mitchell SM, et al. Uptake of communitybased, self-collected HPV testing vs . visual inspection with acetic acid for cervical cancer screening in Kampala, Uganda: preliminary results of a randomised controlled trial. Trop Med Int Health 2015;20:1355-67.

16 Ogilvie GS, Krajden M, van Niekerk D, et al. Hpv for cervical cancer screening (HPV focal): complete round 1 results of a randomized trial comparing HPV-based primary screening to liquid-based cytology for cervical cancer. Int J Cancer 2017;140:440-8.

17 Chuang LT, Randall TC, Karlan BY. Efforts towards erasing borders in gynecologic cancer? Gynecologic Oncology Reports 2017;21:5-6.

18 Gottschlich A, Rivera-Andrade A, Grajeda E, et al. Acceptability of human papillomavirus self-sampling for cervical cancer screening in an Indigenous community in Guatemala. J Glob Oncol 2017;005629.
19 Sriplung $\mathrm{H}$, Singkham $\mathrm{P}$, lamsirithaworn $\mathrm{S}$, et al. Success of a cervical cancer screening program: trends in incidence in songkhla, southern Thailand, 1989-2010, and prediction of future incidences to 2030. Asian Pac J Cancer Prev 2014;15:10003-8.

20 Virani S, Sriplung $\mathrm{H}$, Bilheem S, et al. Effect of the National screening program on malignancy status of cervical cancer in northern Thailand. Int J Public Health 2018;63:377-85.

21 Virani S, Bilheem S, Chansaard W, et al. National and Subnational population-based incidence of cancer in Thailand: assessing cancers with the highest burdens. Cancers 2017;9:108.

22 Globocan. Thailand cancer fact sheet. Int Agency Res Cancer 2018.

23 Bureau of Democracy Human Rights and Labor. International religious freedom report US Department of State; 2005.

24 Oranratanaphan S, Termrungruanglert W, Khemapech N. Acceptability of self-sampling HPV testing among Thai women for cervical cancer screening. Asian Pac J Cancer Prev 2014;15:7437-41.

25 Phoolcharoen N, Kantathavorn N, Krisorakun W, et al. Acceptability of self-sample human papillomavirus testing among Thai women visiting a colposcopy clinic. J Community Health 2018;43:611-5.

26 Staff U. Unc family health study survey 2010.

27 Organizacion Mundial de Salud. Manual de Vigilancia steps de la OMS: El Método stepwise de la OMS para La Vigilancia de Los Factores de Riesgo de las Enfermedades Crónicas, 2006. Available: http://goo.gl/06Th0Y

28 Qualtrics Software. Qualtrics. Provo, Utah, USA.

29 Herswab Fact Page. Eve medical Inc. Available: http://www.evemedical.com/ [Accessed 4 Sep 2017].

30 Hybribio. 13 high-risk HPV real-time PCR kit 2017.

31 Sukvirach S, Smith JS, Tunsakul S, et al. Population-Based human papillomavirus prevalence in Lampang and Songkla, Thailand. J Infect Dis 2003;187:1246-56.

32 Sudore RL, Mehta KM, Simonsick EM, et al. Limited literacy in older people and disparities in health and healthcare access. J Am Geriatr Soc 2006;54:770-6.

33 Alvarez C, Rozek L, Sriplung H. Differences in prostate tumor characteristics and survival among religious groups in southern Thailand. Cancer Res 2017;77:1-9.

34 Che Y, You J, Zhou S, et al. Comparison of survival rates between Chinese and Thai patients with breast cancer. Asian Pac J Cancer Prev 2014;15:6029-33.

35 Kerdpon D, Sriplung $\mathrm{H}$. Factors related to advanced stage oral squamous cell carcinoma in southern Thailand. Oral Oncol 2001;37:216-21.

36 Khwankong S, Sriplung H, Kerdpon D. Knowledge and health belief attitudes of oral cancer and its screening among at-risk southern Thai Muslims. J Canc Educ 2018;33:615-21.

37 Muangpaisan T, Sriplung H. Social and geographic predictors of cancer survival: a role for a population-based cancer registry in cancer control. Asian Pacific J Cancer Prev 2000;1:319-23.

38 Internal labour office SPD. Thailand: universal health-care coverage scheme 2016. 